\title{
Epistemic Luck and Knowledge
}

\author{
Michael J. Shaffer ${ }^{1}$
}

Published online: 8 February 2022

(c) Springer Nature B.V. 2022, corrected publication 2022

\section{Introduction}

This issue of Acta Analytica contains eight papers written by prominent epistemologists that address various issues having to do with the notion of epistemic luck and its relation to belief and knowledge. The issue of epistemic luck is an old one that can be traced back, at least, to Plato's comments on knowledge in Theatetus and in Meno. However, the issues surrounding epistemic luck and its relation to knowledge were made much more acute by Edmund Gettier's observations in his infamous 1963 paper "Is Justified True Belief Knowledge?" and the introduction of the now infamous Gettier cases therein. That paper initiated a host of increasingly baroque suggestions about the nature of epistemic luck, about how to deal with the problem of epistemic luck, and about how to defuse the threat of Gettier cases. More recently, Duncan Pritchard's important 2005 book Epistemic Luck has once again made the issue of epistemic luck and its relation to knowledge a focal concern of many epistemologists, and, in light of this work in particular, the topic of so-called anti-luck epistemology has become a focal one in epistemology. The intention behind this volume then is to collect recent thinking on this matter by a number of epistemologists who have stressed the importance of addressing the problem of epistemic luck in a variety of contexts. The papers included here by Mylan Engel, Ram Neta, Duncan Pritchard, Jonathan Kvanvig, E. J. Coffman, Tim Black, Moisés Barba and Fernando Broncano-Berrocal, and Michael Shaffer all engage the issue in various ways and the hope is that they advance our understanding of the prospects of anti-luck epistemology. But what exactly is epistemic luck and how does epistemic luck relate to knowledge?

Michael J. Shaffer

shaffermj66@outlook.com

1 Department of Philosophy, Gustavus Adolphus College, OM 104,800 West College Avenue,Saint Peter, Minnesota 56082, USA 


\section{Plato, Gettier Cases and Epistemic Luck}

The decidedly timeworn and orthodox analysis of the nature of knowledge is that knowledge is justified true belief. The earliest versions of this conception of knowledge are found in some of Plato's middle period works and the view was taken to be a bit of epistemological orthodoxy, if there is any such thing. This familiar analysis of knowledge is as follows:

(JTB) S knows that $\mathrm{p}$, if and only if,

(i) $\mathrm{S}$ believes that $\mathrm{p}$,

(ii) $\mathrm{S}$ 's belief that $\mathrm{p}$ is justified, and

(iii) $\mathrm{p}$ is true.

Here, conditions (i), (ii), and (iii) were supposed to be individually necessary and jointly sufficient for knowledge. So, the JTB theory of knowledge is a decompositional conceptual analysis that breaks knowledge down into more primitive and perhaps more well-understood notions (i.e., belief, truth, and justification). On this basis, JTB is supposed to be an informative analysis of the concept of knowledge. It tells us in greater detail what properties knowledge states must exhibit. Moreover, if this analysis is correct, then it would be a useful tool to deploy in order to contrast and critically judge attitudinal states that are not knowledge with those that are knowledge, including various knowledgelike states and states of belief. States of the former sort importantly include true guesses, other unjustified true beliefs, justified beliefs in approximate truths, justified beliefs in strict falsehoods, and the like.

It is in Meno Plato introduces the JTB analysis of the concept of knowledge. ${ }^{1}$ But, this view is also found and discussed in Plato's later dialogue Theatetus. ${ }^{2}$ But, crucially, in the Meno that we find a defense of the JTB analysis in terms of the superior value of knowledge when it is compared to true beliefs that are only true as a matter of luck. So, Plato was to some extent aware of and sensitive to the issue of epistemic luck and its incompatibility with knowledge. The road to Larissa thought experiment is designed, at least in part, to make this point. ${ }^{3}$ We are to suppose that we need to find the way to the city of Larissa and that it is down one of two roads, but that we do not know which road to take to get there. Now we are asked to compare two cases. The first case is where we have only belief that happens to be true as a matter of luck, but not knowledge of the correct path and the second is where we have knowledge of the correct path. Is there any difference between the two cases? It might look as if there is no difference here because the person using lucky true belief to get to Larissa in this case gets there just as does the person who knows the way to Larissa. However, when we generalize from this case, things become clearer. If we suppose that our two

\footnotetext{
${ }^{1}$ Meno 97a-98d, p. 380-382.

2 Theatetus 201a-e, p. 907-908.

${ }^{3}$ Meno 97a-d, p. 380-381.
} 
persons need to get to various cities, say because they are merchants who trade in perishable goods, then it seems easy to see how knowledge of the correct paths is better than guidance based on mere belief. The correctness or truth of mere belief is a matter of luck whereas the correctness of knowledge is not. ${ }^{4}$ The merchant who guides himself by guessing and hoping that his beliefs are true will just as often go the wrong way as he will go the right way. But, the merchant who guides himself by knowledge will always get to the correct place. Thus, Plato establishes that knowledge is superior to beliefs that are true as a matter of luck and that lucky true beliefs are not knowledge.

Plato buttresses this point by considering the statues of Daedalus myth. ${ }^{5}$ The statues of Daedalus were supposed to be fabulously valuable statues that had the odd magical property of disappearing if not tied down. Here we are to make an analogy between two kinds of these mythological statues and the cases of knowledge and mere belief. A tied-down statue of Daedalus is supposed to correspond to knowledge and an untied-down statue is supposed to correspond to mere belief. We are then asked to assess the relative values of knowledge and mere belief in terms of the statues. What we learn is then that an untied statue of Daedalus, while potentially valuable, is nowhere near as valuable as a tied-down statue. The fleeting nature of an untied statue of Daedalus greatly diminishes its value, for its value is not durable. ${ }^{6}$ By analogy, the fleeting nature of mere beliefs that are true as a matter of luck is of little value when compared to the durable value of knowledge and this raises the issue of reliability in relation to knowledge and lucky true belief.

In any case, the JTB analysis was widely taken to be the correct analysis of knowledge from Plato's day until relatively recently, and, in agreement with Plato, it was at least tacitly assumed that the JTB analysis provided adequate resources to discriminate knowledge and lucky true belief. But, in a short 1963 paper, Edmund Gettier showed that the JTB account of knowledge is incorrect. ${ }^{7}$ What Gettier specifically did was to present two cases where conditions (i)-(iii) were met but where our intuitions are supposed to be that the agent in question does not have knowledge because the belief in question is only true as a matter of luck. ${ }^{8}$ In effect, Gettier challenged the sufficiency of the JTB account on this basis. Let us then introduce one of the so-called Gettier cases in order to see how it raises the issue of epistemic luck in the context of JTB. Consider the case of Smith. ${ }^{9}$ We are to suppose that Smith has strong evidence for the claim that Jones owns a Ford. This evidence includes that Jones has always owned a Ford and that Jones has just offered a ride to Smith while driving a Ford. Suppose also that Smith has a friend Brown and that Smith does not know where Brown currently is. So, Smith formulates the following beliefs. Either

\footnotetext{
${ }^{4}$ Meno 97c-d, p. 381.

5 Meno 97d-98c, p. 381-382.

6 Meno 98a, p. 382.

7 Gettier 1963.

8 It is worth mentioning that Gettier's case for the rejection of the JTB account only follows as a deductive consequence given the assumptions of epistemic closure and the idea that one can be justified in holding a false belief.

9 Gettier 1963, 122.
} 
Jones owns a Ford or Brown is in Boston. Either Jones owns a Ford or Brown is in Barcelona. Either Jones owns a Ford or Brown in Brest-Litovsk. All three are entailed by the claim that Jones owns a Ford. But, suppose that Jones does not in point of fact own a Ford, say he is presently driving a rental car. Moreover, by coincidence suppose that unknown to Smith Brown is actually in Barcelona. This means that Smith meets conditions (i)-(iii) of the JTB analysis, but intuitively we do not believe that Smith knows that either Jones owns a Ford or Brown is in Barcelona. What has happened is that Smith's belief has been caused in some inappropriate manner and the truth of his justified belief is, in some important sense of the term, a matter of epistemic luck. Smith randomly guesses that Brown is in Barcelona and it just happens, by luck, to be true.

So, according to Gettier and most practicing epistemologists, it is supposed to be the case that Smith does not know because the truth of the claim that Brown is in Barcelona is a matter of knowledge destroying epistemic luck. Smith meets conditions (i)-(iii), but Smith does not know. We are supposed to share the intuition that Smith does not know and thereby be in a position to see that the JTB analysis of knowledge cannot be correct. In light of this watershed result, practitioners of post-Gettier epistemology became intensely concerned with the offering of an alternative analysis of knowledge, prominently including "fourth condition" analyses (JTB + analyses) that are intentionally designed rule out cases involving epistemic luck as bona fide knowledge, for these epistemologists acknowledge the wrongness of Plato's assumption that the JTB analysis provides adequate resources to disqualify lucky true beliefs as knowledge. ${ }^{10}$ So, this deeply important development in modern epistemology drew attention to the nature of such knowledge destroying epistemic luck and its relation to the orthodox concept of knowledge. Most crucially, it has led to a variety of proposals for how to re-conceptualize knowledge in such a way that it rules out cases involving epistemic luck as knowledge. But, what precisely is the nature of the relationship between epistemic luck and knowledge?

\section{The Incompatibility Thesis and Veritic Epistemic Luck}

The principal problem involving the relation between epistemic luck and knowledge involves what has come to be called the incompatibility thesis. Essentially, this is just the claim that one cannot know a belief the truth of which is merely a matter of luck. The incompatibility thesis can then be stated more clearly as follows:

(IT) Knowledge is incompatible with veritic epistemic luck

However, as should be apparent from IT, the incompatibility thesis concerns only a specific form of luck known as veritic epistemic luck. ${ }^{11}$ Veritic luck is the sort of

\footnotetext{
10 See Unger 1968, Pappas and Swain 1978, Shope, and Neta 2009 for a survey of the variety of postGettier accounts of knowledge.

11 See Engel 2011, Pritchard 2005, and Pritchard 2007.
} 
luck involved in Gettier cases and it pertains to the luckiness of the truth of the relevant propositions involved in such cases, and not, for example, luck as it pertains to having some particular evidence. ${ }^{12}$ As such, veritic epistemic luck is supposed to be knowledge destroying epistemic luck in the sense that if a justified true belief is the result of veritic epistemic luck, then that belief cannot constitute knowledge. Of course, this then raises the crucial issues of just what constitutes veritic epistemic luck and what modifications might be made with respect to JTB in order to rule out justified, true, beliefs that are true as a matter of such luck as knowledge. However, with respect to the first of these issues, this is some disagreement about how to characterize verititc epistemic luck and the two most prominent analyses of veritic epistemic luck are the evidence-based analysis and the modal analysis. The standard epistemic account of veritic epistemic luck is as follows:

(EVEL) $\mathrm{S}$ is veritically luck in believing $\mathrm{p}$ in context $\mathrm{C}$, if and only if, given S's evidence e for $p$, it is just a matter of luck that S's belief that $p$ in $C$ is true. $^{13}$

Alternatively, the modal account of veritic epistemic luck is the modal account of luck is typically understood as follows:

(MVEL) For all S and propositions $p$, the truth of S's belief that $\mathrm{p}$ is veritically epistemically lucky, if and only if, S's belief that $\mathrm{p}$ is true in the actual world wa but false in nearly all possible worlds in which $\mathrm{S}$ formulates the belief that $\mathrm{p}$ in the same manner as in wa. ${ }^{14}$

So, understanding the nature of veritic epistemic luck is crucial in order to understand the incompatibility thesis. Moreover, how one characterizes the nature of veritic epistemic luck impacts the prospects for various JTB + accounts of knowledge qua their ability to defuse Gettier cases and other cases of epistemic luck. Specifically, some prominent recent attempts to deal with epistemic luck, importantly including Pritchard's approach, are founded on MVEL and they appeal the modal concept of epistemic safety in order to deal with the issue of veritic epistemic luck. ${ }^{15}$ So, these approaches add the safety condition to the JTB analysis in order to explain the difference between knowledge and lucky true belief. But, this sort of approach is not the only one extant and there are many other potentially fruitful ways of conceptualizing and dealing with epistemic luck and its relation to knowledge. The papers presented here by Engel, Neta, Pritchard, Kvanvig, Coffman, Black, Barba and Broncano-Berrocal, and Shaffer address these matters in various ways and are intended to advance our understanding of epistemic luck and its relation to belief and knowledge in various ways.

12 See Engel 2011, 21-23.

13 Engel 2011, 22.

14 Engel 2011, 23.

15 See Engel 2011, 25-26, Pritchard 2005, Pritchard 2007 and Rabinowitz 2019. 


\section{References}

Gettier, E. (1963). Is justified true belief knowledge? Analysis, 23, 121-123.

Mylan Engel, M. (2011). "Epistemic luck," The Internet Encyclopedia of Philosophy.

Neta, R. (2009). Defeating the dogma of defeasibility. In P. Greenough \& D. Pritchard (Eds.), Williamson on knowledge (pp. 161-182). Oxford University Press.

Nozick, R. (1981). Philosophical explanations. Harvard University Press.

Pappas, G., \& Swain, M. (1978). Essays on knowledge and justification. Cornell University Press.

Pritchard, D. (2005). Epistemic luck. Oxford University Press.

Pritchard, D. (2007). Anti-luck epistemology. Synthese, 158, 277-298.

Rabinowitz, D. (2019). "The safety condition for knowledge," The Internet Encyclopedia of Philosophy. https://iep.utm.edu/. Accessed 2/5/2022

Shope, R. (1983). The analysis of knowing. Princeton University Press.

Unger, P. (1968). An analysis of factual knowledge. Journal of Philosophy, 65, 157-170.

Publisher's Note Springer Nature remains neutral with regard to jurisdictional claims in published maps and institutional affiliations. 